\title{
Towards a Planar Cruciform Specimen for Biaxial Characterisation of Polymer Matrix Composites
}

\author{
M. R. L. Gower ${ }^{1, a}$ and R. M. Shaw ${ }^{1, b}$ \\ ${ }^{1}$ Materials Division, National Physical Laboratory, Hampton Road, Teddington, Middlesex, \\ TW11 OLW, United Kingdom. \\ amichael.gower@npl.co.uk, ${ }^{\mathrm{b}}$ richard.shaw@npl.co.uk
}

Keywords: polymer matrix composites, biaxial, cruciform, digital image correlation

\begin{abstract}
This paper details work undertaken towards the development of a standard test method for the biaxial response of planar cruciform specimens manufactured from carbon fibre-reinforced plastic (CFRP) laminates and subject to tension-tension loading. Achieving true biaxial failure in a cruciform specimen without the need for the inclusion of a stress raiser, such as a hole, in the gaugesection, is a subject attracting much research globally and is by no means a trivial exercise. Coupon designs were modelled using finite element analysis (FEA) in order to predict the stress and strain distributions in the central region of the specimen. An Instron biaxial strong-floor test machine was used to test the specimens. Strain gauges were used to measure the strain in the specimen arms and to assess the degree of bending. Digital image correlation (DIC) was used to measure the full-field strain distribution in the central gauge-section of the specimen and this was compared to values measured using strain gauges. The strain readings obtained from strain gauges, DIC and FEA predictions were in good agreement and showed that the strain distribution was uniform in the central gauge-section, but that strain concentrations existed around the tapered thickness zone. These regions of strain concentration resulted in interlaminar failure and delamination of the laminate propagating into the specimen arms.
\end{abstract}

\section{Introduction}

Most composite components experience multi-axial loading during their service life and are often fabricated from multi-directional laminates. Existing composite test standards for generating mechanical design data are predominantly uniaxial in scope, and although several laboratories are proposing standard methods for biaxial characterisation, there is currently no standard protocol in place. A world-wide exercise to compare different failure theories for multidirectional polymer composites has already been undertaken [1] and it is particularly important that the experimental data used for these intercomparisons are robust. There are several methods suitable for creating multi-axial loading, including the use of axial forces and pressure (internal/external) using tube specimens, plate or cruciform type biaxial configurations, and full rig systems applying combinations of axial, bending and/or twisting loads. Whilst considerable work has been conducted using tubular specimens, recent moves by industry towards both larger and lighter composite structures requires the planar performance of these materials to be better understood. Currently, the biaxially loaded cruciform specimen has been identified as of most interest with much effort targeted toward achieving a valid failure mode in an un-notched specimen. A potential means of achieving a valid failure without the need for notching is through the use of specimens with a locally thinned gauge-section formed by either milling or ply drop-off. Milling material from specimens is not only laborious and expensive, but it is also difficult to machine the gauge-section to the desired ply level. The alternative technique, whereby plies are dropped-off during the lay-up process has the advantage that the surface of the gauge-section is guaranteed to be of the desired ply orientation. However, this production technique is also laborious and it is difficult to accurately position plies around the centre of the specimen. 


\section{Specimen Design}

In general, planar specimens suitable for biaxial characterisation should satisfy a number of requirements, namely; (i) the shape of the test specimen should be cruciform with a central gaugesection, as shown in Fig. 1, (ii) fibre reinforcement should be present in both the loading directions, (iii) the shape and dimensions of the test specimen should be such that when loaded in tension in the primary and secondary loading directions simultaneously, a uniform biaxial strain field is produced within a centrally located gauge-section of minimum $20 \mathrm{~mm}$ diameter, and (iv) final failure should occur within the gauge-section and is deemed to have occurred when the load carrying capacity of the specimen drops by $20 \%$.

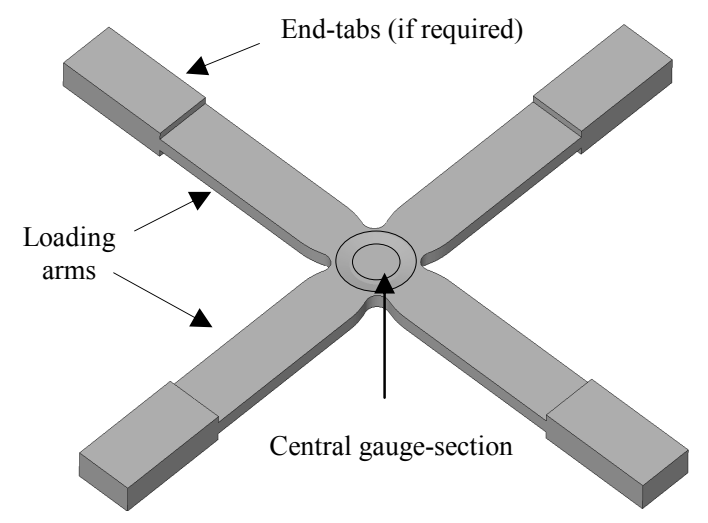

Figure 1. Generic form of biaxial cruciform specimens

With these stipulations in mind, coupons were designed with specimen arms all of the same length and a circular thickness waisted central gauge-section. The lay-up of the laminates for all specimens was $\left[+45^{\circ} / 0^{\circ} /-45^{\circ} / 90^{\circ}\right]_{2 \mathrm{~s}}$. The size and geometry of the test specimens was limited by the maximum size of square panel $(300 \times 300 \mathrm{~mm})$ that could be manufactured in the NPL autoclave. The size of the gauge-section and arm width was limited by the load capacity $(50 \mathrm{kN})$ of the multiaxial test facility.

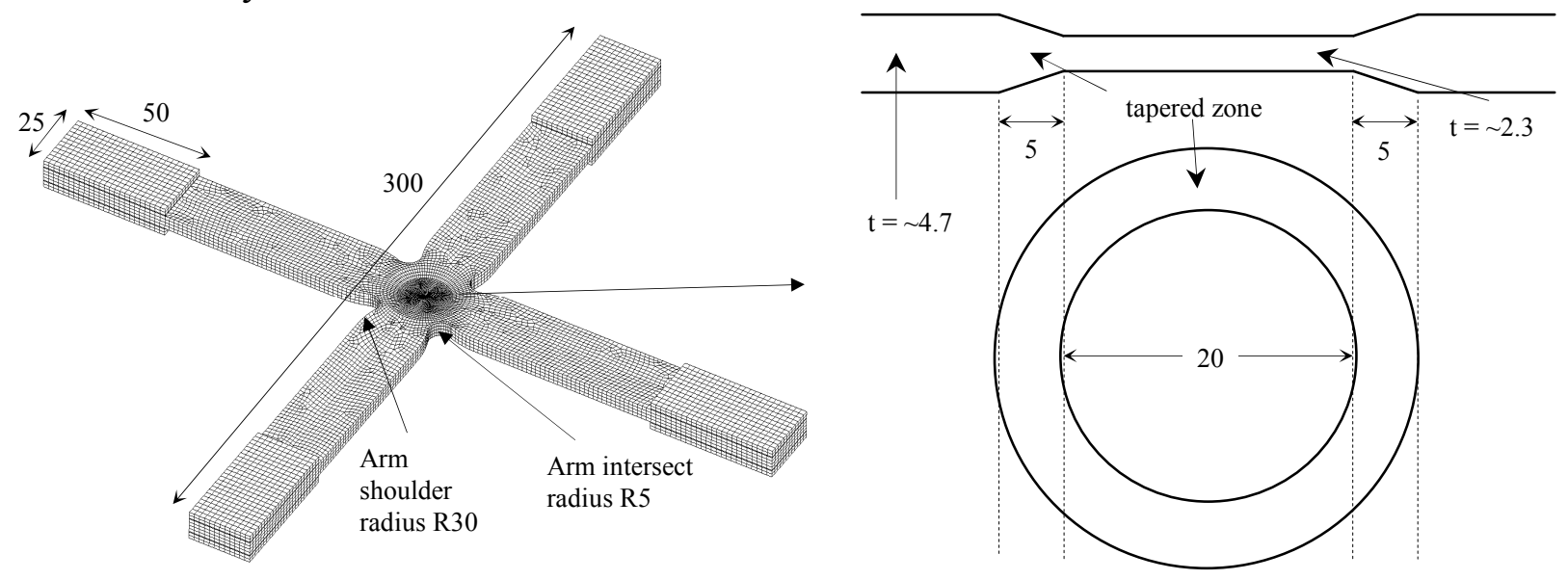

Figure 2. Schematic of $25 \mathrm{~mm}$ specimen design and detail of gauge-section

Initially, a coupon with $50 \mathrm{~mm}$ wide arms and a circular gauge-section $40 \mathrm{~mm}$ in diameter was designed in order to give a relatively large area of uniform strain in the centre of the specimen in which biaxial strain measurements could be made. However, in order to reduce the load required to fail the biaxial specimens, a smaller gauge-section design was adopted (Fig. 2). This design has 25 $\mathrm{mm}$ wide arms and a circular gauge-section $20 \mathrm{~mm}$ in diameter. The specimen width/length was 300 
$\mathrm{mm}$. The design of the radius at the intersection of the arms was changed to an intruding radius of 5 $\mathrm{mm}$ with an arm shoulder radius of $30 \mathrm{~mm}$. The protruding radius was chosen to reduce the stress transfer between specimen arms via the $\pm 45^{\circ}$ plies and promote failure in the gauge-section rather than at the radius of the arms. This approach had shown potential in work reported by Smits et al [2]. The thickness of the central gauge-section was reduced from 4.7 to $2.3 \mathrm{~mm}$ via a tapered zone 5 $\mathrm{mm}$ in length.

Specimen Preparation. The material used was SE84 LV unidirectional carbon fibre-reinforced epoxy pre-preg supplied by Gurit Holdings AG. Test panels, 300 x 300 x $\sim 4.7 \mathrm{~mm}$, were autoclave manufactured at NPL following material supplier's guidance. The waisted gauge-section was created by milling away material in $0.1 \mathrm{~mm}$ increments from both sides of the specimen until the correct depth profile had been achieved. All specimens were extracted from cured laminates using water jet profiling and end-tabbed using $2 \mathrm{~mm}$ thick Tufnol 10G/40® woven glass fibre-reinforced epoxy material.

Finite Element Analysis (FEA). A 3D elastic finite element analysis was undertaken for the biaxial coupon design using LUSAS Composite software. End-tabs and a $0.25 \mathrm{~mm}$ thick adhesive bondline were included in the model. Elastic ply data for the SE84 LV material system (measured at NPL) were used as input into the FE model. A $20 \mathrm{MPa}$ through-thickness stress was applied to the end-tab regions to replicate the clamping pressure applied in the experimental tests via hydraulic grips. The FEA analysis was undertaken to predict strain distributions for comparison to values measured using strain gauges and digital image correlation (DIC).

\section{Biaxial Testing and Results}

Multi-axial Test Facility. The multi-axial test facility (Fig. 3(a)) consists of a tee-slotted cast iron strong floor, upon which are mounted four hydraulic actuators each with a dynamic load rating of $\pm 50 \mathrm{kN}$ and a stroke of $\pm 50 \mathrm{~mm}$. Fig. 3(b) shows the set-up used for biaxial testing.

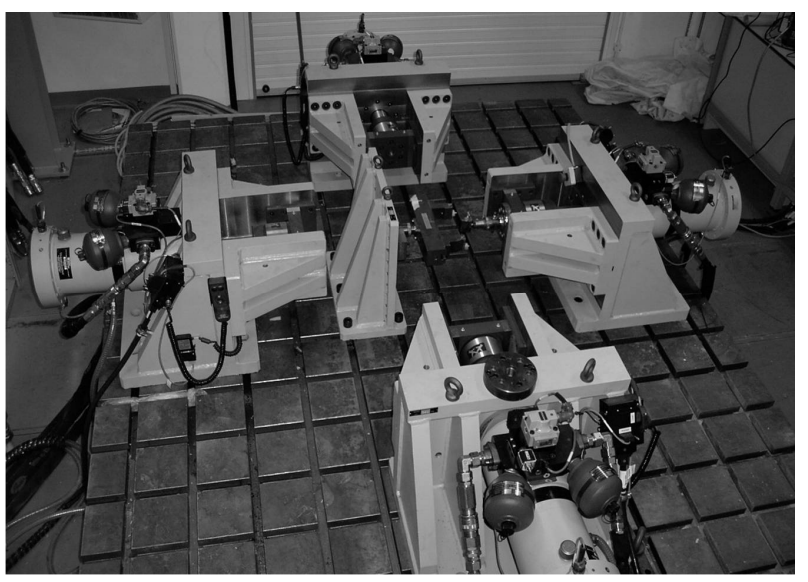

(a)

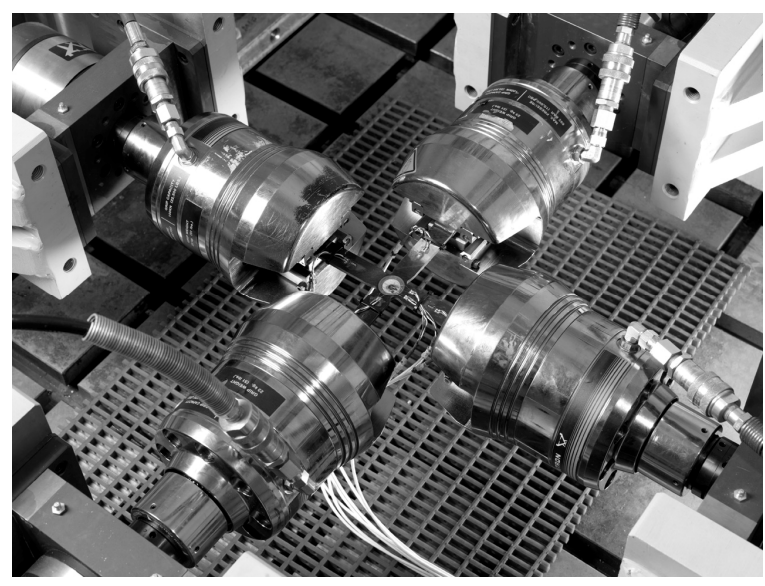

(b)

Figure 3. (a) NPL multi-axial test facility and (b) biaxial test set-up with hydraulic grips

Strain Measurements. A combination of strain gauges and DIC were used for strain measurements. In the central gauge-section, one side of the specimen was used for DIC measurements whilst strain gauges were used on the opposite face. Specimens analysed with DIC were sprayed with white, grey and black paint to achieve a unique surface finish with a variety of grey levels. A LaVision ${ }^{\circledR}$ DIC system was used with a 5 megapixel video camera to map 2D strain distributions. Images were recorded throughout the tests and all strain results were calculated 
relative to the first image recorded at zero load. DIC was used to measure the strain over the central gauge section of specimens.

A series of $2 \mathrm{~mm}$ gauges were bonded to all 4 arms in the positions shown in Fig. 4. These gauges were used to monitor the degree of in-plane and through-thickness bending. The configuration of the gauges, bending analysis and limits for an acceptable level bending were adopted from the uni-axial tensile standard ISO 527-5 [3]. It is noted that the combined (in-plane and through-thickness) limit level of bending of $<3 \%$ is considered too strict for a test where load is applied in orthogonal directions. However, the analysis is of value in that it provides a means for assessing the alignment of the test set-up and specimen. In addition to the arm gauges, a single triaxial gauge was used for measuring strain in this region of the specimen.

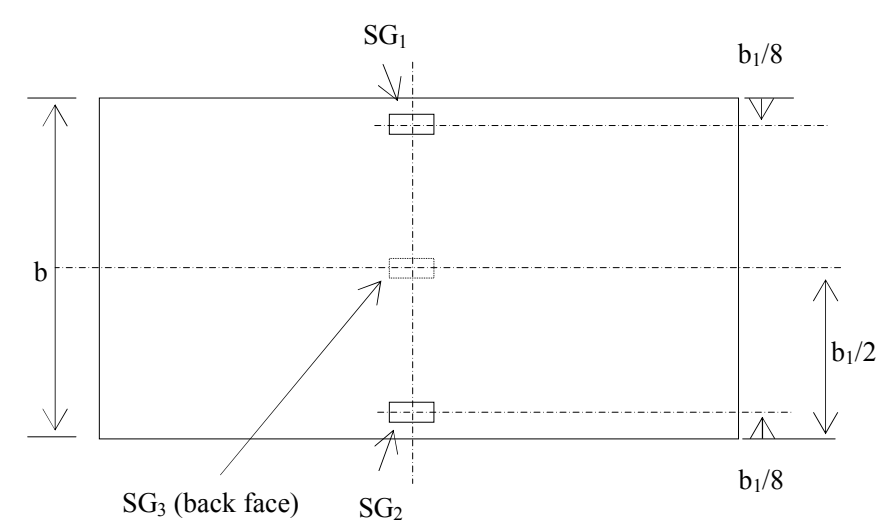

(a)

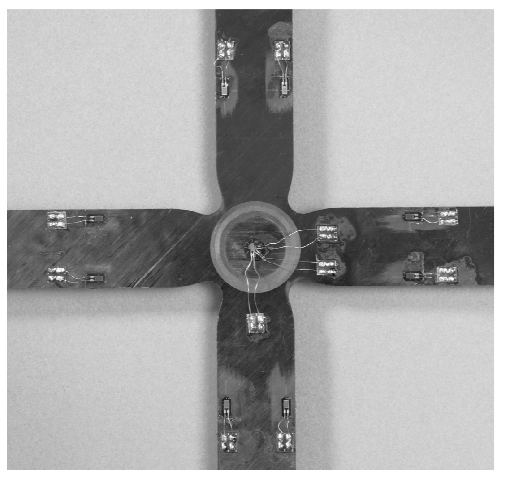

(b)

Figure 4. Strain gauge positions: (a) arm positions and (b) strain gauged $25 \mathrm{~mm}$ specimen

Elastic Measurements. Hydraulic grips were fitted to the biaxial set-up so as to improve the alignment of the biaxial set-up and uniformity of gripping. The load and therefore strain ratio in the two orthogonal directions was set as 1:1. The load profile for both axes was a monotonic ramp up to $10 \mathrm{kN}$. The tests were undertaken in position control using a displacement rate on each axis of 1 $\mathrm{mm} / \mathrm{min}$ until the $10 \mathrm{kN}$ load had been reached. The specimen was then held under load for 10 seconds before unloading. Images for DIC analysis were recorded throughout each test at a frequency of $2 \mathrm{~Hz}$.

Initial elastic trials showed a difference in the measured strains in the central gauge section in the two orthogonal directions. This was an unexpected result as the strains should be the same in both directions. On closer inspection of the specimen it was observed that the top surface of the locally thinned gauge-section was not that of a $+45^{\circ}$ ply, but of a $90^{\circ}$ ply instead. Additional machining was undertaken to remove the remainder of the $90^{\circ}$ ply on both sides of the specimen and to reveal the $+45^{\circ}$ ply surface. Subsequent loading trials of the re-machined specimen resulted in strain measurements in much better agreement in both directions indicating that the specimen machining was improved compared to the initial state. A 1:1 loading ratio test was undertaken and the degree of bending was checked. The bending results at the maximum load of $10 \mathrm{kN}$ (in both axes) are shown in Table 1.

Table 1. Assessment of bending in $25 \mathrm{~mm}$ specimen at $10 \mathrm{kN}$

\begin{tabular}{|l|c|c|c|c|}
\hline \multirow{2}{*}{ Bending component } & \multicolumn{4}{|c|}{ Bending (\%) } \\
\cline { 2 - 5 } & Arm 1 & Arm 2 & Arm 3 & Arm 4 \\
\hline In-plane, $\mathrm{B}_{\mathrm{b}}$ & 2.75 & 3.94 & 5.81 & 9.12 \\
\hline Through-thickness, $\mathrm{B}_{\mathrm{h}}$ & 0.46 & 0.95 & 3.02 & 0.45 \\
\hline Total, $\mathrm{B}_{\mathrm{b}}+\mathrm{B}_{\mathrm{h}}$ & 3.21 & 4.89 & 8.84 & 9.56 \\
\hline
\end{tabular}


With the degree of bending deemed to be as good as could be achieved with the experimental set-up used, the strains in the central gauge-section were measured using strain gauges and DIC on the same specimen. These strain measurements were then compared to the FEA model. The comparisons of measured and predicted strains were performed at 2.5, 5, 7.5 and $10 \mathrm{kN}$. The results are shown in Table 2 and generally the strains are in good agreement. The FEA predicts the strains in the $\mathrm{x}$ - and $\mathrm{y}$ - directions should be the same, however there were differences in the strains in the two directions as measured by the strain gauges and DIC, with the strain in the $\mathrm{x}$ - direction lower than that in the $y$ - direction. This was reasoned to be due to difficulties in accurately machining the gauge-section to the exact depth across the gauge-section area.

Table 2. Comparison of $\varepsilon_{\mathrm{xx}}$ and $\varepsilon_{\mathrm{yy}}$ strains in gauge-section

\begin{tabular}{|c|c|c|c|c|c|c|}
\hline \multirow{2}{*}{ Load (kN) } & \multicolumn{3}{|c|}{$\boldsymbol{\varepsilon}_{\mathbf{x x}}$ (microstrain) } & \multicolumn{3}{c|}{$\boldsymbol{\varepsilon}_{\mathbf{y y}}$ (microstrain) } \\
\cline { 2 - 7 } & Gauge & DIC & FEA & Gauge & DIC & FEA \\
\hline 2.5 & 403 & 447 & 426 & 442 & 484 & 427 \\
\hline 5.0 & 804 & 872 & 850 & 886 & 943 & 854 \\
\hline 7.5 & 1206 & 1298 & 1280 & 1330 & 1402 & 1280 \\
\hline 10.0 & 1608 & 1723 & 1703 & 1774 & 1860 & 1709 \\
\hline
\end{tabular}

Fig. 5 and 6 show comparisons of the FEA predicted and DIC strain maps in the $\mathrm{x}$ - and $\mathrm{y}-$ direction at $10 \mathrm{kN}$, respectively. It was not possible to use the same contour levels for the DIC and FEA strain maps, and therefore regions of equivalent strain level do not exactly colour match. The predicted and measured strain maps were in good agreement and show a fairly uniform strain field in the gauge-section. Also, regions of high strain were observed corresponding to the tapered section and at the radius of the specimen arms.

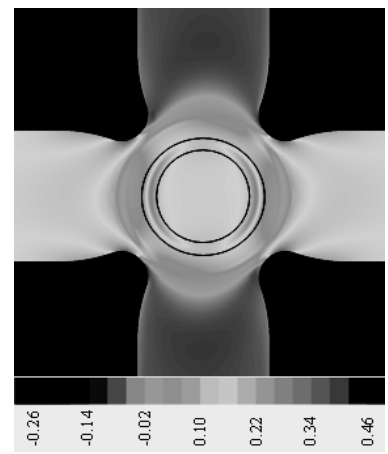

(a)

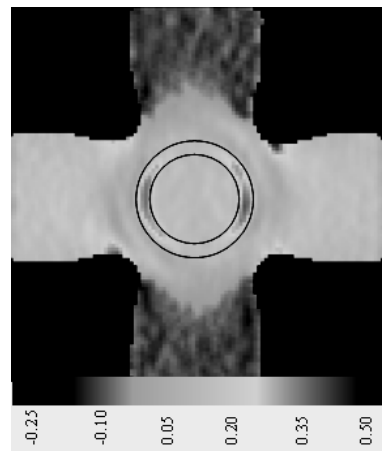

(b)

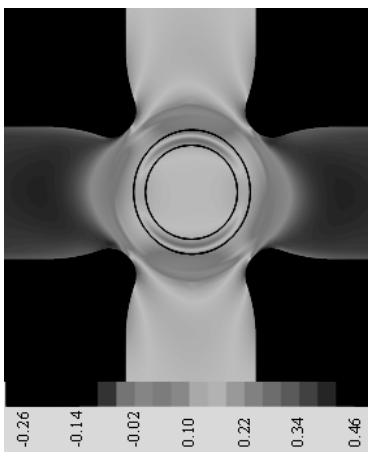

(a)

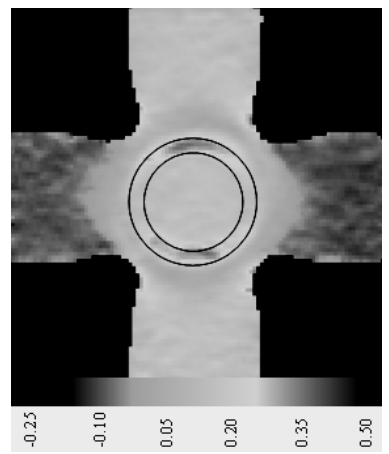

(b)

Figure 5. $\varepsilon_{\mathrm{xx}}(\%)$ by: (a) FEA and (b) DIC

Figure 6. $\varepsilon_{y y}(\%)$ by: (a) FEA and (b) DIC

Having completed the elastic measurements a specimen was loaded to failure using a loading ratio of 1:1 under position control. A displacement rate of $1 \mathrm{~mm} / \mathrm{min}$ was used in both axes. The specimen failed at a load of $28.9 \mathrm{kN}$ as a result of interlaminar failure occurring in the tapered thickness section causing delamination failure to propagate into the specimen arms. Also, failure was observed at the radius of one of the arms. The failure locations are in good agreement with the strain concentrations predicted using FEA and measured using DIC. The specimen did not fail in the specimen gauge-section, and thus the mode of failure was not considered to be representative of a true biaxial failure. 


\section{Conclusions}

DIC has been successfully used to measure the full-field strain distribution and showed that the strain was fairly uniform in the gauge-section of the specimens. DIC also detected the presence of high interlaminar strains around the tapered thickness zone, which was in good agreement with FEA predictions. These strain concentrations resulted in interlaminar failure and delamination of the laminate propagating into the specimen arms. This failure mode has also recently been observed in specimens of similar geometry by Makris et al [4] and Ramault et al [5]. To overcome this failure mode, Ramault et al [5] have attempted to use a specimen that does not feature a thickness reduction in the gauge-section. Instead, the specimen is clad with an adhesively bonded end-tabbing material everywhere except the gauge-section. However, it was shown that specimen failure then occurred in the adhesive bond-line between the tabbing material and the base laminate and again, true biaxial failure did not result. It is clear from this study that more work is required before a standard biaxial characterisation method for planar specimens can be recommended.

\section{Acknowledgements}

The authors acknowledge the financial support provided by United Kingdom Department for Business, Innovation and Skills (National Measurement Office), as part of the Characterisation Programme. The authors would like to express their gratitude to Gurit Holdings AG, Qinetiq, Vrije Universiteit Brussel (VUB) and NPL colleagues Dr Bill Broughton and Dr Graham Sims.

\section{References}

[1] M. J. Hinton, P. D. Soden and A. S. Kaddour, 'Failure Criteria in Fibre-Reinforced-Polymer Composites: The World-Wide Failure Exercise, (Oxford UK, Elsevier Ltd., 2004).

[2] A. Smits, D. Van Hemelrijck, T. Philippidis and A. Cardon, 'Design of a cruciform specimen for biaxial testing of fibre reinforced composite laminates', Composites Science and Technology V66, pp 964-975, 2006.

[3] BS EN ISO 527-5 Plastics - Determination of tensile properties - Part 5: Test conditions for unidirectional fibre-reinforced plastic composites

[4] A. Makris, C. Ramault, D. Van Hemelrijck, E. Lamkanfi and W. Van Paepegem, 'Damage Evolution on Composite Cruciform Specimens Under Quasi-Static Biaxial Loading', ICCM-17, 27-31 July 2009, Edinburgh, UK.

[5] C. Ramault, A. Makris, D. Van Hemelrijck, E. Lamkanfi and W. Van Paepegem, 'Effect of Tab Design on the Strain Distribution of a Biaxially Loaded Cruciform Composite Specimen', ICCM-17, 27-31 July 2009, Edinburgh, UK. 